\title{
Cognitive factors predict medication adherence and asthma control in urban adolescents with asthma
}

This article was published in the following Dove Press journal:

Patient Preference and Adherence

\section{Hyekyun Rhee' \\ Mona N Wicks ${ }^{2}$ \\ Jennifer S Dolgoff ${ }^{2}$ \\ Tanzy M Love ${ }^{3}$ \\ Donald Harrington ${ }^{3}$}

'University of Rochester School of Nursing, Rochester, NY, USA; ${ }^{2}$ College of Nursing, University of Tennessee Health Science Center, Memphis, TN, USA; ${ }^{3}$ Department of Biostatistics and Computational Biology, University of Rochester Medical Center, Rochester, NY, USA
Correspondence: Hyekyun Rhee University of Rochester School of Nursing, 60I Elmwood Avenue, Box SON, Rochester, NY |4642, USA

Tel +I 5852763775

Fax + I 585273 I270

Email hyekyun_rhee@urmc.rochester. edu
Purpose: Adolescents with asthma often report poor medication adherence and asthma control. Cognitive factors embedded in the social cognitive theory including self-efficacy, outcome expectations, and barrier perceptions may explain poor asthma outcomes in this population. This study was performed to examine the extent to which these cognitive factors are intercorrelated and explain medication adherence and asthma control in urban adolescents.

Patients and methods: A total of 373 urban adolescents (12-20 years) with asthma completed questionnaires measuring asthma-related self-efficacy, outcome expectations, barrier perceptions, medication adherence, and asthma control. Multiple linear regression was conducted to examine the extent to which the three cognitive factors predicted medication adherence and asthma control after controlling for covariates including age, sex, household income, and age at diagnosis.

Results: Participants' ages were on average $14.68( \pm 1.94)$ years; $50 \%$ were female, and most (78.6\%) were African American. Higher self-efficacy associated with lower barrier perceptions and higher outcome expectations ( $r=0.50, p<0.001 ; r=-0.26, p<0.001$, respectively). Self-efficacy predicted better asthma control $(B=-0.098, p=0.004)$ and adherence $(B=0.426$, $p=0.011)$, whereas barrier perceptions predicted poorer asthma control $(B=0.13, p<0.001)$ and adherence $(B=-0.568, p<0.001)$. Self-efficacy independently predicted fewer missed doses $(B=-0.621, p=0.006)$, and barrier perception independently predicted asthma control $(B=0.12$, $p<0.001)$ and adherence $(B=-0.519, p<0.001)$.

Conclusion: Improving medication adherence and asthma control among adolescents may require a multifaceted approach. Interventions focused on increasing self-efficacy and addressing barriers, actual or potential, to medication adherence could ameliorate asthma disparities in urban adolescents.

Keywords: self-efficacy, outcome expectation, barrier perception, social cognitive theory

\section{Introduction}

Asthma represents an increasingly serious health problem in children and adolescents in the USA, contributing to rapidly rising morbidity and mortality over the past 20 years. ${ }^{1,2}$ In 2015 , over 6 million children younger than 18 years, or $8.4 \%$ of the population, had a current asthma diagnosis, and about 3 million children suffered asthma attacks. ${ }^{3}$ Asthma remains a common health concern in many adolescents, ${ }^{4}$ with $10 \%$ of the US adolescents 12-17 years of age reporting a current asthma diagnosis. ${ }^{3}$ Adolescents suffer greater asthma-related morbidity and mortality than other age groups. ${ }^{5,6}$ Urban adolescents suffer a disproportionate burden of asthma. ${ }^{1,5,7,8}$ Among adolescents, inadequate self-management, particularly poor medication adherence, contributes to 
adverse asthma outcomes. Therefore, exploring modifiable factors associated with treatment adherence is an important first step to fostering adherence in adolescents and improving clinical outcomes.

According to social cognitive theory (SCT), people intentionally contribute to their functioning life circumstances and therefore their health. ${ }^{9}$ Within this theoretical perspective, Bandura asserts that cognitive factors affect people's willingness to implement new behaviors. These cognitive processes include self-efficacy, outcome expectations, and perceptions about barriers to achieving desired behaviors. Within this theoretical perspective, observing reinforcement or punishment of behavior in others influences an individual's expectations about future implementation of the action. Thus, people see the negative and positive consequences associated with performing particular acts, forming outcome expectations. Bandura also theorized that individuals' conviction that they can accomplish an observed behavior (eg, self-efficacy) and the effort it takes to perform the behavior (eg, barrier perceptions) along with outcome expectations influence their willingness to attempt the behavior.

Individuals with high levels of self-efficacy set goals and remain dedicated to them, visualize success, approach difficult tasks as opportunities, efficiently refine their approach when faced with adversity, and recover from setbacks without losing their convictions. ${ }^{9,10}$ Studies have shown that adolescents' adherence to asthma treatment correlates to self-efficacy. ${ }^{11-15}$ Similarly, Sleath et al $^{16}$ found that children with high asthma self-management and self-efficacy had significantly greater controller medication adherence compared to those with low self-efficacy. Further, Bursch et al ${ }^{17}$ found that children's age positively associated with their asthma management self-efficacy.

Barrier perceptions refer to a person's perceptions about personal, situational, and environmental impediments to attaining the intended outcomes. ${ }^{18}$ Studies have suggested that perceptions regarding barriers of an intrapersonal, interpersonal, situational, or environmental nature can adversely impact medication adherence and outcomes in children and adolescents with chronic conditions including asthma. ${ }^{12,19}$ The egocentric nature of adolescents could make young people more self-critical of their limitations and environmental adversities, placing them at risk for heightened barrier perception. Therefore, examining the extent to which barrier perception predicts medication adherence and asthma control in adolescents exposed to the chronic personal and situational adversities present in urban environments is critical.

Outcome expectations are a person's beliefs about the likelihood and value of the consequences of a chosen behavior. ${ }^{10}$ In studies of adults with chronic health conditions, outcome expectations were linked with adherence to desired behaviors, resulting in better clinical outcomes. ${ }^{20-22}$ However, findings are less conclusive in pediatric populations diagnosed with chronic conditions. One study found no association, ${ }^{16}$ whereas another study ${ }^{23}$ reported significant relationships between outcome expectations and medication adherence in adolescents with diabetes. Previous studies, to date, have not explored the relationships between the concepts of outcome expectations and medication adherence for asthma outcomes, particularly in urban adolescents.

To date, no studies have examined the interrelationships among these three cognitive concepts in association with treatment adherence in adolescents with asthma. Typically, investigators tend to focus on each of these cognitive factors individually rather than simultaneously, although Bandura ${ }^{9}$ hypothesizes associations among all three concepts. Therefore, the extent to which these cognitive factors collectively and synergistically influence medication adherence and asthma control in adolescents with asthma warrants exploration. The aims of this study were to 1) examine the relationships among the three cognitive factors and 2) determine the extent to which these three cognitive factors (self-efficacy, outcome expectations, and barrier perceptions) predict medication adherence and asthma control in urban adolescents. We hypothesized that these three cognitive factors correlate with each other and that self-efficacy and outcome expectations positively associate with medication adherence and asthma control, whereas barrier perceptions negatively relate to these variables.

\section{Patients and methods}

\section{Settings and sample}

Subject recruitment took place in three US metropolitan cities located in New York (NY), Maryland (MD), and Tennessee (TN). Subjects were recruited through clinician or school referrals, word of mouth, or direct recruitment at community venues or clinics. We screened adolescents who were 12-20 years of age and had physician-diagnosed asthma for eligibility. To establish that the diagnosis was current, we enrolled adolescents who reported asthma-related healthcare utilization in the past 12 months preceding enrollment. Persistent asthma was an eligibility criterion. We defined persistent asthma as current use of a control medication or the presence of a relevant asthma control classification criterion established by the National Asthma Education and Prevention Program (NAEPP). ${ }^{24}$ Eligibility criteria also included primary residence in the participating urban cities based on zip codes or school districts and ability to understand spoken and written English. The presence of other chronic comorbid conditions affecting the cardiopulmonary 
system (eg, cancer, cystic fibrosis, congenital heart disease), as reported by parents, was an exclusion criterion.

\section{Study measurements}

\section{Asthma expectation scale}

This 15-item scale, informed by SCT, consists of three subdomains (five items each) representing three cognitive constructs - self-efficacy, outcome expectations, and barrier perceptions. ${ }^{18}$ The subscales measure each of these constructs specific to the context of five asthma management behaviors including 1) keeping medical appointments for asthma; 2) avoiding triggers; 3) adhering to treatment procedures; 4) recognizing early signs of asthma attacks; and 5) managing an attack properly. Response options reflect a 9-point scale from 1 (not at all) to 9 (extremely). The questionnaire, developed initially for caregivers of children with asthma, had reasonable validity and reliability $(\alpha=0.66-0.72) .{ }^{18}$ For the current study, we modified the wording, making the measure suitable for adolescent respondents (eg, from "your child" to "you"). Cronbach alphas for the subscales were 0.67 for self-efficacy, 0.77 for outcome expectations, and 0.70 for barrier perceptions in the current sample. We computed mean scores for each subscale, with higher scores indicating greater self-efficacy, outcome expectations, and barrier perceptions.

\section{Asthma Control Questionnaire}

Juniper et $\mathrm{al}^{25}$ developed this questionnaire in order to gauge the range of clinical impairment of people with asthma based on their experience of the disease. The original survey contains seven items considered the most important for determining asthma control. Participants rate their experience on a 7-point scale, from 0 (no impairment) to 6 (extreme impairment). We removed one item, FEV1\% predicted prebronchodilator, as obtaining these data were not feasible in this community-based study. This six-item version, without the FEV1\% item, performed similarly to the full version, yielding identical clinical results, which justified using the revised version without loss of validity. ${ }^{26}$ The questionnaire has been validated in children and adolescents 6-16 years of age. ${ }^{27}$ The mean score of the six items was computed, with higher scores indicating greater impairment. Cronbach alpha of the measure in the current sample was 0.86 .

\section{Medication adherence}

We administered Horne's four-item Medication Adherence Report Scale (MARS) ${ }^{28}$ to measure adolescents' self-reported adherence in general rather than obtaining specific data on whether or when they took their medication. The scale estimates adherence based on the extent of an individual's general tendency to forget to take or intentionally alter or miss medication. Responses to each item reflect a five-point scale ranging from 1 (very often) to 5 (never). The sum scores ranging from 4 to 20 were computed, with higher scores indicating higher levels of adherence. Cronbach alpha in the current sample was 0.77. In addition to the MARS, adolescents were asked to report controller medication doses missed in the prior 2 weeks to estimate adherence in a more clinically meaningful way. Only adolescents who reported a prescribed controller medication completed the MARS and missed doses measured, as daily adherence is not appropriate for rescue medication use. Adolescents also disclosed the main reason for nonadherence.

\section{Study procedure}

The Institutional Review Board (IRB) of each of the participating academic institutions (University at Buffalo IRB, Johns Hopkins Medicine IRB, and University of Tennessee Health Science Center IRB) and a coordinating center (University of Rochester Research Subjects Review Board) approved the study protocol (ClinicalTrials.gov identifier: NCT02293499). Before data collection, written and informed consent and assent were obtained from parents and adolescents under 18 years of age, respectively, while those 18-20 years of age independently provided written and informed consent. Study staff collected questionnaire data during in-person appointments in the project office, in the home, or other community location. Parents provided sociodemographic (age, sex, socioeconomic status, and race) and asthma-related (medication, age at asthma diagnosis, and family history of asthma) information, and adolescents completed the study questionnaires providing data on the three cognitive factors, medication adherence, and asthma control.

\section{Data analysis}

Summaries and visualizations of study variables were examined for systematic patterns and outliers. No outliers were discovered in the data. Pearson correlations were calculated between the three cognitive measures and sociodemographic variables. The distribution of asthma control data measured by the Asthma Control Questionnaire (ACQ) was skewed, suggesting the need for a log-transformation for model fitting. Multiple linear regression was used to predict medication adherence report (MAR), missed doses, and log-transformed asthma control scores. In these models, the variables sex, current age, age at asthma diagnosis, and household income served as covariates, given their possible 
associations with at least one of the outcome measures. Age was significantly associated with ACQ score; older teens reported better asthma control $(p=0.048)$. Females had significantly worse asthma control (higher ACQ scores, $p<0.001$ ) and worse medication adherence (lower MAR, $p=0.026$ ). Nine independent models were fit to predict each of the three outcomes (MAR, missed doses, and asthma control) using each cognitive measure as a predictor along with the covariates. Then, three joint models were fit using all three cognitive indicators, conditionally, and the covariates. Estimates of slopes and their 95\% CIs were calculated along with their $p$-values. Residual analysis was evaluated to look for assumption violations and model outliers. These models had no substantial departures from the assumptions of the statistical tests. Additional models were fit with an interaction term between younger (12-14 years) and older (15-20 years) teens and each cognitive measure. There was no significant evidence of interactions between age and cognitive measures for the three outcomes, so only models without interactions are reported.

\section{Results}

\section{Sample characteristics and descriptions of study variables}

A total of 373 adolescents from Buffalo, NY $(n=154)$, Baltimore, MD ( $n=100)$, and Memphis, TN ( $n=119)$ enrolled in the study. Table 1 summarizes the demographic characteristics of the sample. Participants' ages were on average $14.68( \pm 1.94)$ years; $50 \%$ were female, and most $(78.6 \%)$ were African American. Most (57\%) of the participants reported $<\$ 30,000$ of annual household income, and 19\% of parents had completed less than a high school education. The three sites were not significantly different in age distribution and gender composition. The Buffalo site enrolled significantly more white adolescents $(31 \%)$ compared to Baltimore $(5 \%)$ or Memphis site $(2 \%)(p<0.001)$, and family income was significantly lower in the Baltimore site than Buffalo and Memphis sites $(p=0.02)$. Because of the close relationship between race and family income $(r=0.28, p<0.001)$ and family income being adjusted for as a covariate, the race variable was not included in the subsequent regression models. Seventy-two percent reported an asthma diagnosis by the age of 6 . According to the NAEPP classification criteria, $65 \%(n=240)$ reported uncontrolled asthma, of which $44 \%$ $(n=162)$ had poorly controlled asthma. Most of the sample $(n=275,74 \%)$ reported using at least one controller medication, and almost all participants $(n=363,98 \%)$ reported having a prescribed short-acting bronchodilator.
Table I Sociodemographic characteristics of the sample and descriptive statistics of outcome measures $(\mathrm{N}=373)$

\begin{tabular}{|c|c|}
\hline $\begin{array}{l}\text { Sociodemographic factors/ } \\
\text { outcome measures }\end{array}$ & $\begin{array}{l}n \% \text {, mean, } \\
S D \text {, range }\end{array}$ \\
\hline \multicolumn{2}{|l|}{ Sex } \\
\hline Male, n (\%) & $187(50)$ \\
\hline Female, n (\%) & $186(50)$ \\
\hline \multicolumn{2}{|l|}{ Race } \\
\hline White, n (\%) & $55(14.8)$ \\
\hline \multicolumn{2}{|l|}{ Nonwhite } \\
\hline Black or African American, n (\%) & $293(78.6)$ \\
\hline Other, n (\%) & $4(1.0)$ \\
\hline Multirace, $\mathrm{n}(\%)$ & $21(5.6)$ \\
\hline Hispanic/Latino, n (\%) & $31(8.3)$ \\
\hline Age, mean (SD) & $14.68(1.94)$ \\
\hline $12-14, \mathrm{n}(\%)$ & $173(46.4)$ \\
\hline I5-20, n (\%) & $200(53.6)$ \\
\hline Age at asthma diagnosis, mean (SD) & $4.12(4.20)$ \\
\hline$\leq 6$ years old, $\mathrm{n}(\%)$ & $267(72)$ \\
\hline$>6$ years old, $\mathrm{n}(\%)$ & $105(28)$ \\
\hline \multicolumn{2}{|l|}{ Annual household income } \\
\hline$\leq \$ 10,000, \mathrm{n}(\%)$ & $105(28.1)$ \\
\hline$>\$ 10,000$ and $\leq \$ 30,000, n(\%)$ & $106(28.4)$ \\
\hline$>\$ 30,000$ and $\leq \$ 70,000, \mathrm{n}(\%)$ & $103(27.6)$ \\
\hline$>\$ 70,000, n(\%)$ & $48(12.9)$ \\
\hline Missing, n (\%) & $\mathrm{II}(0.3)$ \\
\hline Self-efficacy, mean (SD), range & 6.86 (1.35), $2.2-9.0$ \\
\hline Barrier perception, mean (SD), range & 4.04 (I.77), I.0-8.4 \\
\hline Outcome expectation, mean (SD), range & 7.49 (1.33), 2.8-9.0 \\
\hline MAR, mean (SD), range & 12.73 (4.09), 4-20 \\
\hline \multicolumn{2}{|l|}{ Missed medication days in 2 weeks, } \\
\hline \multicolumn{2}{|l|}{ Asthma Control Questionnaire total, } \\
\hline mean (SD), range & 8.60 (6.74), $0-31$ \\
\hline
\end{tabular}

Abbreviation: MAR, medication adherence report.

Table 1 shows the descriptive statistics of the study variables. The most common reasons for not taking controller medication were "forgot to take it" $(50 \%)$ followed by "don't need it" (38\%) and "don't want to take it" (4\%).

\section{Relationships between cognitive factors and asthma control and medication adherence}

The three cognitive factors correlated with each other as shown in Table 2. Self-efficacy was positively associated with outcome expectations and negatively associated with barrier perceptions. No significant relationship was found between outcome expectations and barrier perceptions. Also, no significant associations were found between the three cognitive factors and the sociodemographic variables (age, sex, and family income) or the age at asthma diagnosis, except the negative relationship found between barrier perceptions and age, indicating younger adolescents reported greater barrier perceptions. 
Table 2 Correlations among three cognitive factors and relationships between each of the cognitive variables and demographic factors

\begin{tabular}{lllllll}
\hline Cognitive factors & Self-efficacy & $\begin{array}{l}\text { Outcome } \\
\text { expectation }\end{array}$ & Age & $\begin{array}{l}\text { Age at } \\
\text { diagnosis }\end{array}$ & $\begin{array}{l}\text { Sex } \\
\text { income }\end{array}$ & $\begin{array}{l}\text { Family } \\
\text { Self-efficacy }\end{array}$ \\
Outcome expectation & $0.50^{* *}$ & & 0.06 & -0.03 & -0.05 & -0.02 \\
Barrier perception & $-0.26 * *$ & -0.09 & 0.09 & -0.02 & 0.07 & 0.04 \\
\hline
\end{tabular}

Notes: $*_{p}<0.05 . * * p<0.001$.

\section{Cognitive factors as a predictor of asthma control and medication adherence}

In the independent models, self-efficacy and barrier perception measures significantly associated with asthma control and medication adherence (Table 3). Higher self-efficacy associated with better asthma control and higher medication adherence. Self-efficacy negatively associated with missed doses, but it did not reach statistical significance $(p=0.058)$. Higher barrier perceptions predicted poorer asthma control and lower adherence. No significant associations were found between outcome expectations and the three outcome measures. Outcome expectations marginally associated with better asthma control ( $p=0.06)$, but no association occurred between outcome expectations and medication adherence or missed doses.

In the dependent models (Table 4), associations with each of the three cognitive measures were examined after adjusting for the other two demographic covariates (age, sex, and family income). Lower barrier perceptions after controlling for other cognitive measures and covariates predicted better asthma control and medication adherence. Further, higher self-efficacy controlling for outcome expectations and barrier perceptions predicted a lower number of missed doses. Females had significantly worse asthma control (higher ACQ scores, $p<0.001$ ) and marginally significantly worse medication adherence (lower MAR, $p=0.053$ ) after adjusting for all of the variables in the dependent models.

\section{Discussion}

This study demonstrated that the three cognitive concepts of SCT were related to each other, and that self-efficacy and barrier perception were predictive of medication adherence and asthma control in a sample of urban adolescents. Consistent with an earlier study ${ }^{18}$ of parents of children with asthma, our data showed that while self-efficacy correlated with both barrier perceptions (negative) and outcome expectations (positive), no association occurred between barrier perceptions and outcome expectations. These findings suggest that self-efficacy may be a broader concept encompassing the two other seemingly independent cognitive concepts. Unlike our result, Holden et al's ${ }^{18}$ study does not support the independent nature of outcome expectations and barrier perceptions. The difference between the two studies may be due, in part, to the differences in study samples. The earlier data depended on input from parents of children with asthma, while our data came directly from adolescents. In parents, barrier perceptions could be diminished in the presence of their beliefs that performing self-management activities would bring about positive consequences (outcome expectations) because they have more control over the barriers to having their child take medication or eliminating triggers for their child. In contrast, adolescents may have less control over their barriers to self-management, even though they believe there will be positive outcomes associated with specific self-management activities. A qualitative study would provide insights about teens' understanding of each of the three cognitive concepts and relationships between them, which will help to develop age-appropriate definitions to guide future research. Nonsignificant relationships between the cognitive and sociodemographic factors, except age, are noteworthy. Younger adolescents tended to report greater barrier perceptions. Research is needed to explore the types of obstacles that younger adolescents perceive so that adequate assistance can be offered to address them.

Table 3 Regression coefficients (unstandardized) for asthma control, medication adherence, and missed doses in independent models using each of the cognitive measures as a predictor after adjusting for age, sex, household income, and age at diagnosis

\begin{tabular}{|c|c|c|c|}
\hline Cognitive factors & Asthma control $(95 \% \mathrm{CI})$ & Adherence report $(95 \% \mathrm{Cl})$ & Missed doses $(95 \% \mathrm{Cl})$ \\
\hline Self-efficacy & $-0.098, p=0.004(-0.164,-0.032)$ & $0.426, p=0.0$ II $(0.099,0.754)$ & $-0.362, p=0.058(-0.736,0.013)$ \\
\hline Outcome expectation & $-0.065, p=0.060(-0.132,0.003)$ & $0.169, p=0.321 \quad(-0.165,0.503)$ & $0.115, p=0.556(-0.268,0.497)$ \\
\hline Barrier perception & $0.130, p<0.001(0.08 I, 0.179)$ & $-0.568, p<0.00 \mathrm{I}(-0.8 \mathrm{I} 2,-0.324)$ & $-0.118, p=0.413(-0.403,0.166)$ \\
\hline
\end{tabular}


Table 4 Regression coefficients (unstandardized) for asthma control, medication adherence, and missed doses in omnibus models using three cognitive measures as predictors after adjusting for age, sex, household income, and age at asthma diagnosis

\begin{tabular}{|c|c|c|c|}
\hline Cognitive factors & Asthma control $(95 \% \mathrm{CI})$ & Adherence report $(95 \% \mathrm{Cl})$ & Missed doses $(95 \% \mathrm{Cl})$ \\
\hline Self-efficacy & $-0.045, p=0.250(-0.121,0.032)$ & $0.266, p=0.167(-0.112,0.644)$ & $-0.621, p=0.006(-1.059,-0.183)$ \\
\hline Outcome expectation & $-0.030, p=0.442(-0.105,0.046)$ & $-0.017, p=0.928(-0.389,0.355)$ & $0.395, p=0.073(-0.037,0.828)$ \\
\hline Barrier perception & $0.120, p<0.001(0.070,0.170)$ & $-0.519, p<0.001(-0.770,-0.267)$ & $-0.216, p=0.146(-0.507,0.076)$ \\
\hline
\end{tabular}

Consistent with earlier studies, ${ }^{16,29-31}$ we found that higher self-efficacy correlated with better asthma control and better self-reported medication adherence. However, when considered simultaneously with barrier perceptions and outcome expectations, self-efficacy no longer predicted reported adherence or asthma control, suggesting that the contribution of self-efficacy to those outcomes can be accounted for by barrier perception in the model. Therefore, it seems that improving self-efficacy alone without addressing other cognitive concepts including outcome expectations and perceptions about the barriers to self-care behavior may be insufficient to improve treatment adherence or asthma control. Existing evidence suggests that adolescents' self-efficacy for asthma self-management tasks does not consistently translate into desired outcomes, particularly when unaccompanied by proper knowledge and skills training that can enhance treatment expectations and eliminate barriers to actually performing these tasks. For instance, self-efficacy about controller medication use did not predict medication adherence in minority adolescents with persistent asthma. ${ }^{32,33}$ Similarly, in a study by Alexander et al, ${ }^{34}$ children's self-efficacy regarding inhaler use did not make a difference in their inhaler technique when compared with those reporting low confidence. Interestingly, we found that high self-efficacy predicted fewer missed doses, another measure of medication adherence. Unlike the adherence report scale, the MARS, that assesses adherence in a general sense, the measure of missed doses concerns a specific number of days of nonadherence. It appears that those with high self-efficacy tend to skip fewer doses, although the effect of self-efficacy on adherence, in general, may not be realized without addressing outcome expectations and barrier perceptions. The different relationship with self-efficacy between these two measures of adherence is unknown and underscores the need to explore the various ways in which self-efficacy affects medication adherence specifically and in general.

We found barrier perceptions to be a predictor of poor medication adherence and asthma control even after controlling for self-efficacy and outcome expectations, suggesting the unique roles of barrier perceptions in medication adherence and asthma control. Although high self-efficacy could diminish perceptions about barriers to self-management to some extent, ${ }^{12}$ our finding implies that fostering asthma-related self-efficacy would be insufficient to address barrier perceptions in adolescents. Adolescents encounter multiple barriers to adherence such as lack of knowledge about asthma and its treatment or inadequate skills to coordinate, organize, and execute asthma management tasks. ${ }^{32,35,36}$ Additionally, a sense of invincibility coupled with a tendency to seek instant gratification and a desire for normalcy also pose challenges to treatment adherence. ${ }^{37}$ Also in play are social barriers associated with peer pressure, risktaking behaviors, and diminishing parental support, which have all been reported to present challenges to medication adherence in adolescents with asthma. ${ }^{19,38-43}$ Ever-growing psychosocial boundaries and competing social demands taking priority in their lives ${ }^{12,41,44,45}$ may distract adolescents from managing their disease. Therefore, it is no surprise that we found forgetfulness as the most common barrier to medication adherence as in many other studies of adolescents with asthma, ${ }^{12,33,41,44-46}$ along with medication side effects, fatigue, or aversion to taking medication. ${ }^{47}$ Given the host of intraand interpersonal barriers threatening adolescents' optimum self-management of asthma, promoting asthma-related selfefficacy alone is by no means adequate to improve treatment adherence. Self-efficacy to effectively manage issues arising from the psychosocial milieu can be equally important, if not more so, to ameliorate poor treatment adherence ubiquitous in adolescents with asthma. Because of the serious implications for adherence and asthma control, early identification of barriers perceived by adolescents is essential along with appropriate assistance, guidance, and supervision to address these barriers.

Of the various concepts within SCT, outcome expectations have received the least attention, particularly in pediatric asthma literature. This study demonstrated outcome expectations to be the least compelling cognitive concept in relation to treatment adherence and asthma control. We found that a marginal association between outcome expectations and symptom control disappeared when barrier perceptions and 
self-efficacy were entered into the model. This finding and the strong correlation between outcome expectations and self-efficacy suggest a conceptual overlap between them, particularly in their relationship to adherence and symptom control. The literature is mixed on the relationship between outcome expectations and adherence to self-management behaviors across a range of chronic diseases in children. ${ }^{48}$ Although some studies reported nonsignificant relationships between outcome expectations and treatment adherence in adolescents with asthma, ${ }^{16,31}$ others showed the positive association between outcome expectations and medication adherence in adolescents with chronic conditions including asthma. ${ }^{49}$ The inconsistent findings among studies may be due, in part, to varying definitions of outcome expectations resulting in differences in operationalization, or different chronic conditions under consideration. A concept analysis of the construct of outcome expectations in the context of asthma self-management might provide greater conceptual clarity. This could then inform the adequate operationalization of the concept generalizable across future studies investigating the roles of outcome expectations in improving treatment adherence and illness outcomes in adolescents with asthma.

This study has several limitations that warrant caution in interpreting findings. First, the study relied exclusively on self-reported data. Future research should reevaluate the relationship between cognitive factors and objective measures of medication adherence (eg, metered dose count device) and asthma control (eg, pulmonary function measures). Second, the cognitive measures used in this study are by no means perfect; in particular, the borderline internal consistency $(\alpha=0.67)$ for the self-efficacy subscale raises concern. However, given the small number of items covering a broad range of asthma management tasks, the modest value of this alpha is expected. ${ }^{18}$ Third, given the cross-sectional nature of the study design, we cannot make causal inferences about the relationships between the cognitive predictors and our outcome measures. Although we hypothesized cognitive factors would predict medication adherence as well as asthma control, it is also equally plausible that poorly controlled asthma could compromise a sense of self-efficacy and magnify the perception of barriers. Finally, because most of our sample comprised African American adolescents of low-income families living in urban communities, the generalizability of study findings to general populations is not warranted.

Overall, cognitive concepts, particularly self-efficacy and barrier perceptions, appear to have important clinical implications for asthma care in adolescents with asthma. Treatment adherence and asthma control in young people can be improved by modifying these cognitive factors. Notably, the unique contribution of barrier perceptions independent of self-efficacy to adherence and asthma control underscores the importance of a focused intervention to identify and ameliorate potential barriers.

\section{Conclusion}

This study sheds light on the potential roles of cognitive factors, particularly self-efficacy and barrier perceptions, in medication adherence and asthma outcomes in adolescents, supporting hypothesized relationships described in SCT. Although underlying determining mechanisms for the observed associations warrant further research, our findings underscore the clinical importance of adolescents' cognitive appraisal of the disease and its management. A tailored intervention designed to modify adolescents' negative perceptions, while strengthening positive cognitive properties such as self-efficacy through skill-building training seems essential to improving asthma outcomes. Clinicians need to be vigilant in detecting and addressing patient-perceived barriers to asthma management, whether actual or potential, to improve treatment adherence in adolescents. In addition, periodic assessment of the capacity to perform a wide range of self-management tasks and overcome psychosocial challenges to adherence is necessary to gauge and ensure the adequacy of self-efficacy that translates to proper disease management behavior. Continuous efforts to promote and strengthen positive cognitive assets could ultimately lead to reducing asthma morbidity.

\section{Acknowledgments}

The authors thank Dr Annette Grape for her expertise and time in preparing the data set for analysis, and Mr Curtis Roby for his thoughtful editorial assistance. They would also like to express their gratitude to adolescent participants who willingly shared their data with the study team. This work was supported by the National Institute of Health/National Institute for Nursing Research (grant number: R01NR014451). Part of the data reported in this manuscript has been presented as a poster titled "Cognitive concepts predicting medication adherence and asthma control in inner city adolescents" in Sigma Theta Tau International 28th International Nursing Research Congress held in Dublin in July 2017.

\section{Disclosure}

The authors report no conflicts of interest in this work. 


\section{References}

1. Akinbami LJ, Moorman JE, Liu X. Asthma prevalence, health care use, and mortality: United States, 2005-2009. Natl Health Stat Report. 2011;32:1-14

2. Moorman JE, Akinbami LJ, Bailey CM, et al. National surveillance of asthma: United States, 2001-2010. Vital Health Stat. 2012;(35):1-58.

3. Center for Disease Control and Prevention. Most recent asthma data. Available from: https:/www.cdc.gov/asthma/most_recent_data.htm. Accessed June 20, 2017.

4. Morgan WJ, Stern DA, Sherrill DL, et al. Outcome of asthma and wheezing in the first 6 years of life: follow-up through adolescence. Am J Respir Crit Care Med. 2005;172:1253-1258.

5. Akinbami LJ, Moorman JE, Garbe PL, Sondik EJ. Status of childhood asthma in the United States, 1980-2007. Pediatrics. 2009;123 Suppl 3: S131-S145.

6. Akinbami LJ, Schoendorf KC. Trends in childhood asthma: prevalence, health care utilization and mortality. Pediatrics. 2002;110(2):315-322.

7. Milligan KL, Matsui E, Sharma H. Asthma in urban children: epidemiology, environmental risk factors, and the public health domain. Curr Allergy Asthma Rep. 2016;16(4):33.

8. Akinbami LJ, Moorman JE, Simon AE, Schoendorf KC. Trends in racial disparities for asthma outcomes among children 0 to 17 years, 2001-2010. J Allergy Clin Immunol. 2014;134(3):547.e5-553.e5.

9. Bandura A. Human agency in social cognitive theory. Am Psychol. 1989; 44(9):1175-1184.

10. Bandura A. Health promotion by social cognitive means. Health Educ Behav. 2004;31(2):143-164.

11. Williams LK, Joseph CL, Peterson EL, et al. Patients with asthma who do not fill their inhaled corticosteroids: a study of primary nonadherence. J Allergy Clin Immunol. 2007;120(5):1153-1159.

12. Rhee H, Belyea MJ, Cirzynski S, Brasch J. Barriers to asthma selfmanagement in adolescents: relationships to psychosocial factors. Pediatr Pulmonol. 2009;44(2):183-191.

13. Holley S, Morris R, Knibb R, et al. Barriers and facilitators to asthma self-management in adolescents: a systematic review of qualitative and quantitative studies. Pediatr Pulmonol. 2017;52(4):430-442.

14. Mosnaim GS, Pappalardo AA, Resnick SE, et al. Behavioral interventions to improve asthma outcomes for adolescents: a systematic review. J Allergy and Clin Immunol Pract. 2016;4(1):130-141.

15. Knight D. Beliefs and self-care practices of adolescents with asthma. Issues Compr Pediatr Nurs. 2005;28(2):71-81.

16. Sleath B, Carpenter DM, Slota C, et al. Communication during pediatric asthma visits and self-reported asthma medication adherence. Pediatrics. 2012;130(4):627-633.

17. Bursch B, Schwankovsky L, Gilbert J, Zeiger R. Construction and validation of four childhood asthma self-management scales: parent barriers, child and parent self-efficacy, and parent belief in treatment efficacy. J Asthma. 1999;36(1):115-128.

18. Holden G, Wade SL, Mitchell H, Ewart C, Islam S. Caretaker expectations and the management of pediatric asthma in the inner city: a scale development study. Soc Work Res. 1998;22(1):51-59.

19. Logan D, Zelikovsky N, Labay L, Spergel J. The illness management survey: identifying adolescents' perceptions of barriers to adherence. J Pediatr Psychol. 2003;28(6):383-392.

20. Marszalek J, Price LL, Harvey WF, Driban JB, Wang C. Outcome expectations and osteoarthritis: perceived benefits of exercise are associated with self-efficacy and depression. Arthritis Care Res (Hoboken). 2017; 69(4):491-498.

21. O’Brien J, Finlayson K, Kerr G, Shortridge-Baggett L, Edwards H. Using a theoretical approach to identify factors influencing adherence to an exercise programme for adults with venous leg ulcers. J Health Psychol. 2018;23(5):691-700.

22. Stetler C. Adherence, expectations and the placebo response: why is good adherence to an inert treatment beneficial? Psychol Health. 2014; 29(2):127-140.
23. Iannotti RJ, Schneider S, Nansel TR, et al. Self-efficacy, outcome expectations, and diabetes self-management in adolescents with type 1 diabetes. J Dev Behav Pediatr. 2006;27(2):98-105.

24. National Heart, Lung, and Blood Institute. Expert Panel Report 3: guidelines for the diagnosis and management of asthma. 2007. Available from: https:/www.nhlbi.nih.gov/sites/default/files/media/docs/ asthsumm.pdf. Accessed July 10, 2017.

25. Juniper EF, O'Byrne PM, Guyatt GH, Ferrie PJ, King DR. Development and validation of a questionnaire to measure asthma control. Eur Respir J. 1999;14(4):902-907.

26. Juniper EF, Svensson K, Mork AC, Stahl E. Measurement properties and interpretation of three shortened versions of the asthma control questionnaire. Respir Med. 2005;99(5):553-558.

27. Juniper EF, Gruffydd-Jones K, Ward S, Svensson K. Asthma Control Questionnaire in children: validation, measurement properties, interpretation. Eur Respir J. 2010;36(6):1410-1416.

28. Horne R, Weinman J. Patients' beliefs about prescribed medicines and their role in adherence to treatment in chronic physical illness. J Psychosom Res. 1999;47(6):555-567.

29. van Dellen QM, Stronks K, Bindels PJ, Ory FG, van Aalderen WM; PEACE Study Group. Adherence to inhaled corticosteroids in children with asthma and their parents. Respir Med. 2008;102(5):755-763.

30. van der Meer V, van Stel HF, Detmar SB, Otten W, Sterk PJ, Sont JK. Internet-based self-management offers an opportunity to achieve better asthma control in adolescents. Chest. 2007;132(1):112-119.

31. Zebracki K, Drotar D. Outcome expectancy and self-efficacy in adolescent asthma self-management. Child Health Care. 2004;33(2):133-149.

32. Mosnaim G, Li H, Martin M, et al. Factors associated with levels of adherence to inhaled corticosteroids in minority adolescents with asthma. Ann Allergy Asthma Immunol. 2014;112(2):116-120.

33. Koster ES, Philbert D, Winters NA, Bouvy ML. Adolescents' inhaled corticosteroid adherence: the importance of treatment perceptions and medication knowledge. J Asthma. 2015;52(4):431-436.

34. Alexander DS, Geryk L, Arrindell C, et al. Are children with asthma overconfident that they are using their inhalers correctly? J Asthma. 2016;53(1):107-112.

35. Pelaez S, Lamontagne AJ, Collin J, et al. Patients' perspective of barriers and facilitators to taking long-term controller medication for asthma: a novel taxonomy. BMC Pulm Med. 2015;15:42.

36. Wamboldt FS, Bender BG, Rankin AE. Adolescent decision-making about use of inhaled asthma controller medication: results from focus groups with participants from a prior longitudinal study. J Asthma. 2011; 48(7):741-750.

37. Velsor-Friedrich B, Vlasses F, Moberly J, Coover L. Talking with teens about asthma management. J Sch Nurs. 2004;20(3):140-148.

38. Cohen R, Franco K, Motlow F, Reznik M, Ozuah PO. Perceptions and attitudes of adolescents with asthma. J Asthma. 2003;40(2):207-211.

39. Chen E, Chim LS, Strunk RC, Miller GE. The role of the social environment in children and adolescents with asthma. Am J Respir Crit Care Med. 2007;176:644-649.

40. Mulvaney SA, Ho YX, Cala CM, et al. Assessing adolescent asthma symptoms and adherence using mobile phones. J Med Internet Res. 2013;15(7):e141.

41. Blaakman SW, Cohen A, Fagnano M, Halterman JS. Asthma medication adherence among urban teens: a qualitative analysis of barriers, facilitators and experiences with school-based care. J Asthma. 2014; 51(5):522-529.

42. Foster JM, Smith L, Bosnic-Anticevich SZ, et al. Identifying patientspecific beliefs and behaviours for conversations about adherence in asthma. Intern Med J. 2012;42(6):e136-e144.

43. Yang TO, Sylva K, Lunt I. Parent support, peer support, and peer acceptance in healthy lifestyle for asthma management among early adolescents. J Spec Pediatr Nurs. 2010;15(4):272-281.

44. Naimi DR, Freedman TG, Ginsburg KR, Bogen D, Rand CS, Apter AJ. Adolescents and asthma: why bother with our meds? J Allergy Clin Immunol. 2009;123(6):1335-1341. 
45. Edgecombe K, Latter S, Peters S, Roberts G. Health experiences of adolescents with uncontrolled severe asthma. Arch Dis Child. 2010; 95(12):985-991.

46. Panzera AD, Schneider TK, Martinasek MP, et al. Adolescent asthma self-management: patient and parent-caregiver perspectives on using social media to improve care. J Sch Health. 2013;83(12):921-930.

47. Hanghoj S, Boisen KA. Self-reported barriers to medication adherence among chronically ill adolescents: a systematic review. J Adolesc Health. 2014;54(2):121-138.
48. Law GU, Tolgyesi CS, Howard RA. Illness beliefs and self-management in children and young people with chronic illness: a systematic review. Health Psychol Rev. 2014;8(3):362-380.

49. Riekert KA, Rand CS. Electronic monitoring of medication adherence: when is high-tech best? J Clin Psychol Med Settings. 2002;9(1): $25-34$.

\section{Publish your work in this journal}

Patient Preference and Adherence is an international, peer-reviewed, open access journal that focuses on the growing importance of patient preference and adherence throughout the therapeutic continuum. Patient satisfaction, acceptability, quality of life, compliance, persistence and their role in developing new therapeutic modalities and compounds to optimize clinical outcomes for existing disease states are major areas of interest for the journal. This journal has been accepted for indexing on PubMed Central. The manuscript management system is completely online and includes a very quick and fair peer-review system, which is all easy to use. Visit http://www. dovepress.com/testimonials.php to read real quotes from published authors.

\footnotetext{
Submit your manuscript here: http://www.dovepress.com/patient-preference-and-adherence-journal
} 